\title{
Kadınlar İçin Birinci Basamak Sağlık Hizmeti Memnuniyet Anketi Türkçe Geçerlilik ve Güvenilirliği
}

\author{
Dilek Küçük Alemdar®e, Funda Kardaş Özdemir²®
}

'Giresun Üniversitesi, Sağlık Bilimleri Fakültesi, Ebelik Bölümü, Giresun, Türkiye

${ }^{2}$ Kafkas Üniversitesi, Sağlık Bilimleri Fakültesi, Hemşirelik Bölümü, Kars, Türkiye

Dilek Küçük Alemdar, Doç. Dr. Funda Kardaş Özdemir, Dr. Öğr. Üyesi

İetişim:

Doç. Dr. Dilek Küçük Alemdar

Giresun Üniversitesi, Sağlık Bilimleri Fakültesi, Ebelik Bölümü, Giresun, Türkiye

Tel: +904543613788

E-Posta: dilekkucuk@atauni.edu.tr

Gönderilme Tarihi : 06 Haziran 2017

Revizyon Tarihi : 19 Temmuz 2017

Kabul Tarihi ： 24 Temmuz 2017
ÖZET

Amaç: Bu çalışma Kadınlar İ̧̧in Birinci Basamak Sağlık Hizmeti Memnuniyet Anketi'nin Türkçe'ye uyarlanması amacıyla metodolojik olarak yapılmıştır.

Materyal-Metod: Araştırmanın evrenini, Temmuz 2015-Mayıs 2016 tarihleri arasında bir devlet hastanesinde doğum yapan, araştırmanın seçim kriterlerine uyan anneler oluşturmuştur. Araştırmanın örneklemini; doğum sonrası 2 hafta ile 2 ay arasında hastaneye başvuran, çalışmaya katılmayı kabul eden 327 anne oluşturmuştur. Araştırma verilerinin toplanmasında "Anne-Bebek Bilgi Formu" ve "Kadınlar İçin Birinci Basamak Sağlık Hizmeti Memnuniyet Anketi" (KiBBSHMA) kullanılmıştır. Anket toplam 16 maddeden oluşmaktadır. Her bir madde 1 (hiç memnun değilim)'den 5 (son derece memnunum)'e kadar puanlanmaktadır. ölç̧ekten alınan en düşük puan 16, en yüksek puan 80'dir. Ölçeğin dil geçerliği için uzman görüşlerine başvurulmuştur. ölçekte yer alan maddelere ilişkin uzman görüşleri arasında uyum olduğu saptanmıştı. KiBBSHMA'nin güvenilirliğini değerlendirmek için Cronbach Alpha güvenirlik katsayısı ve madde analizleri yapılmışıı.

Bulgular: Ölçeğin yapı geçerliliği için korelasyon analizi yapılmışır ve yapılan analiz sonucunda; 16 maddelik ölçeğin toplam varyansın en çok \%76,89'unu açıklayabildiği bulunmuştur. Ölç̧ğin güvenirliliği için madde-toplam puan korelasyon değerlerinin 0,427-0,785 arasında ve Cronbach Alpha değerinin 0,93 olduğu saptanmıştır.

Sonuç: Kadınlar Iç̧in Birinci Basamak Sağık Hizmeti Memnuniyet Anketi'nin Türkçe geçerlilik ve güvenirliğinin yüksek olduğu bulunmuştur. Anketin postpartum dönemde annelerin kendileri ve bebeklerine verilen sağık hizmetinden duydukları memnuniyetin değerlendirilmesinde kullanılması önerilmektedir.

Anahtar sözcükler: Kadın, birinci basamak sağık hizmeti, memnuniyet, geçerlilik, güvenilirlik

\section{TURKISH VALIDITY AND RELIABILITY OF PRIMARY CARE SATISFACTION SURVEY FOR WOMEN}

\section{ABSTRACT}

Objective: This study was conducted methodologically for adapting the Primary Care Satisfaction Survey for Women into Turkish.

Material-Method: The population of the study consisted of mothers who gave birth in a maternity hospital between July 2015 and May 2016 and met the inclusion criteria. The sample of the study consisted of 327 mothers who applied to the hospital in the postpartum period of 2 weeks- 2 months and agreed to participate in the study. The data of the study were collected by using "Parent-Infant Information Form" and "the Primary Care Satisfaction Survey for Women (PCSSW). The survey consists of a total of 16 items. Each item is scored from 1 (not satisfied at all) to 5 (highly satisfied). While the lowest score obtained from the survey was 16 , the highest score was 80 . Expert opinions were consulted for the language validity of the survey. It was determined that there was a coherence among expert opinions regarding the items in the survey. Cronbach's Alpha reliability coefficient and item analyses were performed for evaluating the reliability of PCSSW.

Results: Correlation analysis was performed for construct validity of the survey and as a result of the analysis, it was determined that it could account mostly for $76.89 \%$ of total variance of the 16 -item survey. For the reliability of the survey; the item-total score correlation values were determined between $0.427-0.785$ and the Cronbach's Alpha value was 0.93 .

Conclusion: It was determined that the Primary Care Satisfaction Survey for Women had a high Turkish validity and reliability. It is recommended to use the survey in evaluating the mothers' satisfaction with healthcare services provided to them and their infants in the postpartum period.

Keywords: Women, primary care, satisfaction, validity, reliability 
ağlık bakım uygulamaları, hizmeti alan birey ile hizmeti sunan sağlık çalışanı arasındaki profesyonel bir etkileşimi içerir (1). Bu etkileşim sırasında bireylerden, uygulamalardan, hizmet sunumundan, iletişimden ya da fiziksel ortamdan kaynaklanan memnuniyet ya da memnuniyetsizlik durumları ortaya çıkar. Topluma dayalı sağlık hizmetlerinde hizmet alan bireylerin memnuniyeti geçerli ve güvenilir araçlar ile ölçülebilir $(1,2)$. Dünya Sağlık Örgütü, birçok kadın ve yenidoğanın doğum sonu bakım alamadığını, anne ölümleri ve hastalık oranlarının yüksek olduğunu ve her yıl 500 binden fazla kadının gebelik ve doğum sonuçları nedeni ile ölmekte olduğu belirtilmektedir. Doğum sonrası bakımın amacı, kadın ve bebeğinin sağlığını korumak ve geliştirmek, sağlık ve sosyal ihtiyaçlarını gidermeye yardımcı olmak için aile ve toplum desteğini geliştirmek olarak belirtilmiştir (3).

Doğum sonu dönemde yaşanan sorunlar göz önünde bulundurulduğunda; anne ve yenidoğana yönelik fiziksel bakımlarının sağlanması, komplikasyonların önlenmesi, aile üyelerinin bu yeni duruma psikososyal uyumunun sağlanması, sağlığın iyileştirilmesi ve önerilerde bulunulabilmesi için sağlık profesyonellerine önemli görevler düşmektedir (4-6). Ayrıca, sağlık profesyonellerinin anneye ve aileye yardım ve rehberlik etmesi gerekmektedir (7).

Memnuniyet, kişiden kişiye değişmekle birlikte kuruluşun görünümü, güler yüzlü, nazik yaklaşım, kullanılan malzemenin kalitesi, hastaya sunulan rahatlık, ortamın temizliği ve hastanın mahremiyetine saygı gösterilmesi ile yakından ilgilidir. Memnuniyet ayrıca bireyin kültürel, sosyal ve psikolojik özelliklerinden de etkilenmektedir. Sağlık hizmeti alan bireyin kişiliği, algıları, geçmiş hastane deneyimleri, tutumları, eğitimi, ait olduğu sosyal çevre ve sosyal ilişkileri memnuniyet düzeyinin önemli belirleyicileri arasında yer almaktadır (8). Hasta memnuniyeti, sağlık kurumlarında hizmet kalitesini değerlendirmede kullanılan temel kriterlerden biri ve sağlık hizmetleri sağlayıcıları için bir gerekliliktir (9). Hasta memnuniyeti, hemşirelik hizmetlerinin kalitesini yükseltmenin yanı sıra hastanın kendi bakımına daha çok katılması ve iyileşme sürecine olumlu katkı sağlaması yönüyle de önemlidir (10). Hasta memnuniyet, hasta ile hizmeti verenlerin etkileşimini, hizmetin sunumunu, hizmetin varlığını, hizmetin sürekliliğini, hizmeti verenlerin yeterliliği ve iletişim özeliklerini içeren çok boyutlu bir kavramdır. Dolayısıyla, memnuniyeti sağlık hizmetlerinin bir sonucu ve genellikle bakım kalitesinin bir göstergesi olarak kabul edilmektedir $(2,11,12)$. Ayrıca sağlık bakım memnuniyeti hastaların aldıkları sağlık hizmeti veya tıbbi bakımla ilgili beklenti, deneyim ve değer yargılarını içeren ve daha çok hastaların algılamalarına dayanan bir kavramdır. Algılanan hasta memnuniyeti daha çok hastaların görüş ve değerlendirmeleridir. Bundan dolayı algılanan hasta memnuniyeti, bakım kalitesine yönelik hasta perspektifi şeklinde nitelendirilmektedir (13). Hasta ve hasta yakınlarının memnuniyet düzeylerinin belirlenmesi; sağlık bakımının planlanması, değerlendirilmesi ve beklentiler doğrultusunda daha nitelikli hizmet sunulması bakımından önemlidir (14).

Türkiye'de hasta merkezli birimlerden hizmet alanların genel ve hemşirelik bakımı memnuniyetlerini ölçen çok sayıda araç bulunmaktadır (2,10,15-18). Ancak birinci basamak sağlık hizmetlerinde kadınların hemşirelik hizmetlerinden memnuniyetini değerlendiren ve Türkçe'ye uyarlanan herhangi bir ölçüm aracına ulaşılamamıştır. Doğumdan sonraki haftalarda sağlık bakım hizmetleri hem yenidoğan hem de anneleri için tavsiye edilmektedir. Bu çalışma doğumdan sonraki haftalardaki anne ve yenidoğanlarına verilen bakımdan memnuniyetlerini ölçmek için geliştirilen çok öğeli bir ölçeğin geçerliliğini ve güvenilirliğini değerlendirmek amacıyla gerçekleştirilmiştir.

\section{Materyal ve metod}

Bu araştırma, Kadınlar İçin Birinci Basamak Sağlık Hizmeti Memnuniyet Anketi'nin Türkçe'ye uyarlanması amacıyla metodolojik olarak yapılmıştır. Araştırmanın evrenini, Temmuz 2015-Mayıs 2016 tarihleri arasında Kars il merkezinde bir devlet hastanesinde doğum yapan, araştırmanın seçim kriterlerine uyan anneler oluşturmuştur. Araştırmanın örneklemini; doğum sonrası 2 hafta ile 2 ay arasında hastaneye başvuran, doğum sonrası birinci basamaktan sağlık hizmeti almış, çalışmaya katılmayı kabul eden 327 anne oluşturmuştur. Ölçek geçerlilik ve güvenilirlik çalışmalarında, örneklem hacminin toplam ölçek madde sayısının 5-10 katı olması önerilmektedir. (19-21). Bu çalışmada, örneklem sayısı ölçek madde sayısının yaklaşık 7 katını ( $\mathrm{n}=327$ kişi) oluşturmaktadır.

Araştırma verilerinin toplanmasında "Anne-Bebek Bilgi Formu" ve "Kadınlar için Birinci Basamak Sağlık Hizmeti Memnuniyet Anketi" kullanılmıştır.

Anne-Bebek Bilgi Formu: Annenin yaşı, eğitim durumu, çocuk sayısı, evlilik süresi, aile tipi, sağlık güvencesi, bebeğin doğum şekli, doğum haftası, cinsiyeti, doğum boyu, doğum kilosu gibi bilgiler yer almaktadır.

Kadınlar için Birinci Basamak Sağlık Hizmeti Memnuniyet Anketi (KiBBSHMA) (Primary Care Satisfaction Survey for Women (PCSSW)): Camacho ve arkadaşları tarafından 2012 
yılında kadınların postpartum dönemde kendilerinin ve yenidoğan bebeklerinin bakımına yönelik aldıkları hizmetten memnuniyetlerini değerlendirmek amacıyla geliştirilmiştir. Anket toplam 16 maddeden oluşmaktadır. Her bir madde 1 (hiç memnun değilim)'den 5 (son derece memnunum)'e kadar puanlanmaktadır. Ölçekten alınan en düşük puan 16, en yüksek puan 80'dir. Ölçekten alınan yüksek puan memnuniyet düzeyinin yüksek olduğunu göstermektedir. Ölçeğin Cronbach's Alpha değeri 0,96'dır (22).

İstatistiksel analizlerde SPSS 21,0 (SPSS, Chicago, IL, USA) kullanılmış olup, $p$ değeri $<0,05$ olduğu durumlarda istatistiksel olarak anlamlı yorumu yapılmıştır. Ölçeğin iç tutarlılığını belirlemek için Cronbach Alfa katsayısı, her bir maddenin toplam puana etkisini görebilmek amacı ile madde-toplam puan korelasyon katsayılarına bakılmıştır.

Araştırmanın yapılabilmesi için ilk olarak Camacho'dan, ölçeğin Türkçe'ye uyarlanması konusunda izin alınmıştır. Ayrıca ilgili kurumdan araştırmanın yapılabilmesi için gerekli izinler alınmıştır. Katılımcılara araştırmanın amacı ve yapmaları gerekenler anlatılmış, çalışmaya katılıp katılmama konusunda özgür oldukları açıklanarak onamları alınmıştır.

\section{Bulgular}

Bu çalışmada annelerin yaşortalaması $28,73 \pm 6,69, \% 33,6$ 'sı lise mezunu, evlilik sürelerinin $7,05 \pm 5,49, \% 8,6$ 'sının sosyal güvencesinin olmadığı ve ortalama çocuk sayısının $1,73 \pm 0,85$ olduğu saptanmıştır. Bebeklerinin $\% 60,2$ 'sinin erkek olduğu ve yarıdan fazlasının $(\% 63,6)$ sezaryenle doğduğu belirlenmiştir. Bebeklerin doğum kilosunun ortalama $3,0853 \pm 689,48 \mathrm{gr}$, doğum boyunun $49,53 \pm 2,69$ $\mathrm{cm}$ ve doğum haftasının $39,11 \pm 1,45$ hafta olduğu tespit edilmiştir.

Dil Geçerliği: Ölçeği alanında uzman iki öğretim üyesi ve bir İngiliz Dil Bilimcisi ayrı ayrı Türkçeye çevirdikten sonra bir araya gelerek, maddeler üzerinde fikir birliğine vararak, bir ölçek haline getirmiş̧ir. Türkçeye çevrilen ölçek iki İngiliz Dil Bilim uzmanı tarafından tekrar İngilizceye çevrilmiştir. Orijinal ölçek ve geri çeviri yöntemi ile elde edilen ölçekler, araştırmacılar ve çevirmenler tarafından birlikte tekrar incelenmiştir. Her bir madde üzerinde anlaşmaya varılarak, ölçeğin Türkçe sürümüne son şekli verilmiştir. Ölçekte yer alan maddelere ilişkin uzman görüşleri arasında uyum olduğu saptanmıştır.

Içerik Geçerliği: Ölçeğin içerik/kapsam geçerliliğinin oluşturulmasında uzman görüşlerine başvurulmuştur. Bu amaçla ölçeğin Türkçe şeklialanında uzman 10 öğretim üyesinin görüşünesunulmuştur. Uzmanlar tarafından yapılan değerlendirme sonrasında, önerilen birkaç kelime düzeltmesi yapılarak ölçeğe son şekli verilmiştir. Daha sonra ölçeğin kapsam geçerliliği için uzman görüşlerinin değerlendirilmesi amacı ile Kapsam Geçerlik İndeksi-KGi (Content Validity Index-CVI) kullanıldı (20). Uzmanlardan maddelerin uygunluğuna göre; 1 puan: uygun değil, 2 puan: biraz uygun (maddenin ve ifadenin uygun şekle getirilmesi gerekli), 3 puan: uygun ancak ufak değişiklikler gerekli, 4 puan: çok uygun şeklinde puan vererek değerlendirme yapmaları istenmiştir. Yapılan analizde KMO değeri 0,83 ve Bartlett's test değeri $p<0,001$ bulunmuştur. Yapılacak değerlendirmede, ölçek maddelerinin \%80'inin 3 ve 4 puan arasında değer alması beklendi (23). Hemşire öğretim üyelerinden elde edilen verilerin yüzdelik değerlendirilmesinde, ölçek maddelerinin \%91'inin 3-4 puan aldığı bulunmuştur. Üç ve dört puandan düşük alan maddeler tekrar gözden geçirilerek küçük değişiklikler yapılmıştır.

Ölçeğin dil ve içerik geçerliği sağlandıktan sonra, ölçekteki ifadelerin anlaşılır olup olmadığını test etmek amacıyla 15 anne üzerinde ön uygulama yapılmıştır. Ön uygulama yapılan grup araştırma kapsamına alınmamıştır. Elde edilen verilere göre ölçeğin Türkçe şeklinin uygulanabilir olduğuna karar verilmiştir.

İç tutarlılık ve madde analizleri; ölçekte 16 maddenin "madde toplam puan korelasyonu" incelendiğinde, maddelerin korelasyon güvenilirlik katsayısının $r=0,594$ ile 0,873 arasında olduğu, arlarındaki ilişkinin pozitif yönde ve istatistiksel olarak ileri düzeyde anlamlı olduğu saptanmıştır ( $p<0,001)$, (Tablo 1). Buna göre ölçekteki maddelerin güvenilirliklerinin yüksek ve aynı değişkeni ölçmeye yönelik oldukları söylenebilir. Ölçekte en düşük madde toplam puan korelasyonuna sahip madde 0,594 ile madde 1 (Sağlık çalışanları ile görüşme sürenizin yeterliliğinden) 'dir. Ölçekte en yüksek madde toplam puan korelasyonu olan madde 0,873 ile madde 11 (Sağlık çalışanlarının, yenidoğan sağlığına ilişkin sorunlar hakkındaki bilgi seviyesinden)'dir.

İç Tutarlılık ve Cronbach Alfa güvenirlik katsayısı; KiBBSHMA'nin ve alt maddelerinin güvenirlik göstergelerinden biri olan iç tutarlılığı test etmek için yapılan analizde; Cronbach Alfa güvenilirlik katsayı alt maddeler için=0,93 ile 0,94 arasında olup tüm ölçek için toplam Cronbach Alfa=0,93 bulunmuştur (Tablo 2). Ölçeğin, 16 maddeye ilişkin toplam varyansın en çok $\% 76,89$ 'sını açıklayabildiği bulunmuştur. 
Tablo 1. Kadınlar için birinci basamak sağlık hizmeti memnuniyet anketi'nin madde toplam puan korelasyonu ve Cronbach's Alpha değerleri

\section{KIBBSHMA}

S1: Sağlık çalışanları ile görüşme sürenizin yeterliliğinden

S2: Sağlık çalışanlarının, soruları duyarlı ve ilgili bir şekilde cevaplama becerisinden

S3: Sağık çalışanlarının, net bir şekilde açıklamada bulunma becerisinden

S4: Sağlık çalışanlarının, konuşurken rahat hissetmenizi sağlama becerisinden

S5: Sağlık çalışanlarına sormanız gereken tüm sorularınızı sormak için ayrılan süreden

S6: Sağlık çalışanlarııın, söylediklerinizi ciddiye alma durumundan

S7: Sağlık çalışanlarının, bebeğiniz ve/veya sizin için farkıı bakım alternatiflerini açıklamak konusundaki istekliliğinden

S8: Sağlık çalışanlarının, kadın sağlığı sorunları hakkındaki bilgi seviyesinden

S9: Sağlık çalışanlarının, zihinsel ve duygusal sağlı̆ınıza da gösterdiği ilgiden

S10: Sağlık çalışanlarının, annelere kendi kendine bakım konusunda verdiği bilgilerden

S11: Sağlık çalışanlarının, yenidoğan sağlığına ilişkin sorunlar hakkındaki bilgi seviyesinden

S12: Yenidoğan bakımı hakkında, sağık çalışanlarından aldığınız bilgi miktarından

S13: Yenidoğan bakımı hakkında, sağlık çalışanlarından aldığınız bilginin anlaşıırlığından

S14: Bebeğinizi beslemek konusunda, sağlık çalışanlarından aldığınız bilgi miktarından

S15: Bebeğinizi beslemek konusunda, sağlık çalışanlarından aldığınız bilginin anlaşılırığından

S16: Bebeğinizi beslemek konusunda, sağlık çalışanlarından aldığınız yardımdan

${ }^{{ }^{*} p}<0,001$

\begin{tabular}{ccc}
$\boldsymbol{R}$ & $\boldsymbol{p}$ & Cronbach's Alpha \\
\hline 0,594 & $0,000^{*}$ & 0,92 \\
0,866 & $0,000^{*}$ & 0,88 \\
0,869 & $0,000^{*}$ & 0,90 \\
0,809 & $0,000^{*}$ & 0,89 \\
0,833 & $0,000^{*}$ & 0,91 \\
0,844 & $0,000^{*}$ & 0,90 \\
0,735 & $0,000^{*}$ & 0,91 \\
0,631 & $0,000^{*}$ & 0,88 \\
0,728 & $0,000^{*}$ & 0,93 \\
0,735 & $0,000^{*}$ & 0,91 \\
0,873 & $0,000^{*}$ & 0,92 \\
0,832 & $0,000^{*}$ & 0,93 \\
0,838 & $0,000^{*}$ & 0,90 \\
0,823 & $0,000^{*}$ & 0,91 \\
0,685 & $0,000^{*}$ & 0,93 \\
0,608 & $0,000^{*}$ & 0,90
\end{tabular}

Tablo 2. Kadınlar için birinci basamak sağlık hizmeti memnuniyet anketi’nin iç tutarllığı ve madde analizi

\begin{tabular}{|c|c|c|c|c|c|c|}
\hline KIBBSHMA & Ortalama & $\begin{array}{c}\text { Standart } \\
\text { sapma }\end{array}$ & $\begin{array}{c}\text { Madde } \\
\text { silinirse ölçeğin } \\
\text { ortalaması }\end{array}$ & $\begin{array}{c}\text { Madde } \\
\text { silinirse ölçeğin } \\
\text { varyansı }\end{array}$ & $\begin{array}{l}\text { Düzeltilmiş } \\
\text { madde toplam } \\
\text { korelasyonu }\end{array}$ & $\begin{array}{c}\text { Madde silinirse } \\
\text { ölçeğin cronbach-Alfa } \\
\text { katsayısı }\end{array}$ \\
\hline S1: Sağlık çalışanları ile görüşme sürenizin yeterliliğinden & 4,29 & 0,99 & 66,71 & 74,38 & 0,43 & 0,94 \\
\hline $\begin{array}{l}\text { S2: Sağlık çalışanlarının, soruları duyarlı ve ilgili bir şekilde } \\
\text { cevaplama becerisinden }\end{array}$ & 4,30 & 0,83 & 66,70 & 75,07 & 0,48 & 0,93 \\
\hline $\begin{array}{l}\text { S3: Sağlık çalışanlarının, net bir şekilde açıklamada } \\
\text { bulunma becerisinden }\end{array}$ & 4,41 & 0,91 & 66,59 & 73,16 & 0,56 & 0,93 \\
\hline $\begin{array}{l}\text { S4: Sağlık çalışanlarının, konuşurken rahat hissetmenizi } \\
\text { sağlama becerisinden }\end{array}$ & 4,38 & 0,83 & 66,62 & 72,54 & 0,66 & 0,93 \\
\hline $\begin{array}{l}\text { S5: Sağlık çalışanlarına sormanız gereken tüm sorularınızı } \\
\text { sormak için ayrılan süreden }\end{array}$ & 4,49 & 0,76 & 66,51 & 74,46 & 0,66 & 0,93 \\
\hline $\begin{array}{l}\text { S6: Sağlık çalışanlarının, söylediklerinizi ciddiye alma } \\
\text { durumundan }\end{array}$ & 4,55 & 0,68 & 66,45 & 74,43 & 0,67 & 0,93 \\
\hline $\begin{array}{l}\text { S7: Sağlık çalışanlarının, bebeğiniz ve/veya sizin için farklı } \\
\text { bakım alternatiflerini açıklamak konusundaki istekliliğinden }\end{array}$ & 4,53 & 0,72 & 66,47 & 73,08 & 0,73 & 0,93 \\
\hline $\begin{array}{l}\text { S8: Sağlık çalışanlarının, kadın sağlığı sorunları hakkındaki } \\
\text { bilgi seviyesinden }\end{array}$ & 4,55 & 0,70 & 66,45 & 73,71 & 0,71 & 0,93 \\
\hline $\begin{array}{l}\text { S9: Sağlık çalışanlarının, zihinsel ve duygusal sağlığınıza } \\
\text { da gösterdiği ilgiden }\end{array}$ & 4,48 & 0,74 & 66,52 & 72,23 & 0,78 & 0,93 \\
\hline $\begin{array}{l}\text { S10: Sağlık çalışanlarının, annelere kendi kendine bakım } \\
\text { konusunda verdiği bilgilerden }\end{array}$ & 4,27 & 1,03 & 66,73 & 70,67 & 0,63 & 0,93 \\
\hline $\begin{array}{l}\text { S11: Sağlık çalışanlarının, yenidoğan sağlığına ilişkin } \\
\text { sorunlar hakkındaki bilgi seviyesinden }\end{array}$ & 4,35 & 0,91 & 66,65 & 69,91 & 0,79 & 0,93 \\
\hline $\begin{array}{l}\text { S12: Yenidoğan bakımı hakkında, sağlık çalışanlarından } \\
\text { aldığınız bilgi miktarından }\end{array}$ & 4,37 & 0,84 & 66,63 & 71,44 & 0,74 & 0,93 \\
\hline $\begin{array}{l}\text { S13: Yenidoğan bakımı hakkında, sağlık çalışanlarından } \\
\text { aldığınız bilginin anlaşılırlığından }\end{array}$ & 4,46 & 0,75 & 66,54 & 72,25 & 0,78 & 0,93 \\
\hline $\begin{array}{l}\text { S14: Bebeğinizi beslemek konusunda, sağlık } \\
\text { çalışanlarından aldığınız bilgi miktarından }\end{array}$ & 4,51 & 0,69 & 66,49 & 73,28 & 0,76 & 0,93 \\
\hline $\begin{array}{l}\text { S15: Bebeğinizi beslemek konusunda, sağlık } \\
\text { çalışanlarından aldığınız bilginin anlaşılırlığından }\end{array}$ & 4,49 & 0,69 & 66,51 & 73,41 & 0,74 & 0,93 \\
\hline $\begin{array}{l}\text { S16: Bebeğinizi beslemek konusunda, sağlık } \\
\text { çalışanlarından aldığınız yardımdan }\end{array}$ & 4,56 & 0,67 & 66,44 & 74,60 & 0,66 & 0,93 \\
\hline
\end{tabular}




\section{Tartışma}

Bir ölçeğin standardize olabilmesi için aranan temel nitelikler ölçeğin geçerliliği ve güvenilirliğidir. Geçerlilik bir ölçme aracının ölçülmek istenen özellik ya da durumu ölçebilme yeteneğidir. Geçerlilik sınanması için pek çok ölçüt vardır (19-21). Araştırmada ölçeğin geçerliliğini değerlendirmek amacıyla dil ve kapsam geçerliliği ile yapı geçerliliği incelenmiştir. Uzman görüşleri sonucunda KiBBSHMA'nin Türkçe formunun dil ve kapsam geçerliliği yönünden uygun bir ölçüm aracı olduğu söylenebilir.

Güvenilirlik analizi değerlendirmede kullanılan ölçütler ölçeğin alfa katsayısı dışında madde ile bütün arasındaki korelasyonlar (Item Total Correlation), madde silinirse bütün ortalamaların değişimi (Meansifltem Deleted) ve madde silinirse güvenirlik katsayısıdır (Reliability Coefficientifltem Deleted). Korelasyon analizi de iki değişken arasındaki doğrusal ilişkiyi test etmek, varsa bu ilişkinin derecesini ölçmek için kullanılan istatistiksel bir yöntemdir. Aralarındaki korelasyonun pozitif ve yüksek olması, maddelerin benzer davranışları örneklediğini ve iç tutarlığın yüksek olduğunu gösterir. Genel olarak korelasyonun 0,30 ve daha yüksek olması beklenir (24). Araştırmada, tüm maddeler için madde-toplam puan korelasyonlarının 0,594 ile 0,873 arasında değiştiği ve arlarındaki ilişkinin anlamlı olduğu görülmektedir $(p<0,001)$. Buna göre ölçekteki maddelerin güvenilirliklerinin yüksek ve aynı değişkeni ölçmeye yönelik oldukları söylenebilir.

Bir ölçeğin güvenilirliğini yansıtan bir diğer ölçüt iç tutarlııktır. İç tutarlıı̆ı değerlendirmek üzere en fazla Cronbach'ın Alfa güvenilirlik katsayısı tercih edilir (20). Bu yöntemde ölçekte yer alan maddelerin homojen bir yapı gösteren bir bütünü ifade etme durumu incelenir. Analiz

\section{Kaynaklar}

1. IIlhan MN, Tüzün H, Aycan S, Aksakal FN, Özkan S. Birinci basamak sağlık kuruluşuna başvuranların sağlık hizmeti kullanma özellikleri ve bazı sosyoekonomik belirteçlerle değişimi: Sağlık reformu öncesi son saptamalar. Toplum Hekimliği Bült 2006;25:33-41.

2. Aksakal T, Bilgili N. Hemşirelik hizmetinden memnuniyetin değerlendirilmesi; jinekoloji servisi örneği. Erciyes Tıp Derg 2008;30:242-9.

3. Who.int. WHO Technical Consultation on Postpartum and Postnatal Care. WHO - World Health Organization. http://whqlibdoc.who.int/ hq/2010/WHO_MPS_10 03_eng.pdf?ua=1 Erişim Tarihi:15.04.2016.

4. Shaw E, Kaczorowski J. Postpartum Care - What's new? Curr Op Obstet Gynecol 2007;19:561-7. [CrossRef]

5. Cashion K. Postpartum physiology \& nursing care of postpartum woman. In: Lowdermilk DL, Perry SE, editors. Maternity \& Women's Health Care 8th ed. Philadelphia: Mosby; 2004. pp.427-67. sonucu elde edilen alfa katsayısı ölçekte yer alan maddelerin varyansları toplamının genel varyansa oranlaması ile bulunan ağırlıklı standart değişim ortalamasıdır (24). Cronbach alfa katsayısı toplam puanın ölçekteki her bir maddeye ait puanlarının toplanması ile elde edilen ölçeklerde maddelerin benzerliğini ya da yakınlığını ortaya koyan bir katsayıdır ve 0 ile 1 arasında değişim gösterir $(25,26)$. Ancak, maddeler arasında negatif bir korelasyon var ise alfa katsayısı negatif çıkar ve bu durumda güvenirlik modeli bozulur (24). Araştırmada, KIBBSHMA'nınCronbach Alfa katsayısının 0,93, alt maddelerin Cronbach Alfa değerinin ise 0,93 ile 0,94 arasında bulunmuştur. Bir başka anlatımla elde edilen bu yüksek iç tutarlılık katsayısı, bu ölçeğin homojenliğinin yeterli düzeyde olduğunu göstermektedir.

\section{Sonuç}

Sonuç olarak, Kadınlar İçin Birinci Basamak Sağlık Hizmeti Memnuniyet Anketi doğumdan sonra kendisine ve yenidoğan bebeğine sağlanan sağlık bakımından bir annenin memnuniyetini ölçmek için kullanılabilecek geçerli ve güvenilir ilk ölçektir. Doğum sonrası bakımdan memnuniyeti değerlendiren önceki ölçekler hem anne hem de bebek bakımıyla ilgili tüm karşılaşmalara ve farklı bakım alanlarına hitap etmekte sınırlı kalmıştır. Bu çalışmada, 16 maddelik Kadınlar İçin Birinci Basamak Sağlık Hizmeti Memnuniyet Anketi'nin Türkçe geçerlik ve güvenirliğinin yüksek olduğu bulunmuştur. Ölçek, güçlü psikometrik özelliklere ve çok yüksek iç tutarlılığa sahiptir ve annelerle yapılan görüşmelerde kolaylıkla uygulanabilir. Anketin postpartum dönemde annelerin kendileri ve bebeklerine verilen sağlık hizmetinden duydukları memnuniyetin değerlendirilmesinde kullanılması önerilmektedir.

6. Taşkın L. Doğum ve Kadın Sağlığı Hemşireliği. XI. Baskı. Ankara: Sistem Ofset Matbaacılık; 2012.

7. Mucuk S, Güler N. Annelerin doğum sonu dönemde bakım beklentileri ve bu beklentilerin hemşireler tarafından karşılanma durumu. Erciyes Üniversitesi Sağlık Bilimleri Derg 2002;11(1):21-30.

8. Engiz O. Sağlık hizmetlerinde hasta tatmini. İçinde: Hayran O, Sur H. Hastane Yöneticiliği. İstanbul: Nobel Tıp Kitapevleri; 1997;61-87.

9. Alhusban MA, Abualrub RP. Patient satisfaction with nursing care in Jordan. J Nurs Manag 2009;17:749-58. [CrossRef]

10. Acaroğlu R, Şendir M, Kaya H, Soysal, E. Bireyselleştirilmiş hemşirelik bakımının hasta memnuniyeti ve sağlığa ilişkin yaşam kalitesine etkisi. İstanbul Üniv Florence Nightingale Hemşirelik Yüksekokulu Derg 2007;15:61-7.

11. Larsson BW, Larsson G, Starrin B. Patients. views on quality of care: a comparison of men and women. J Nurs Manag 1991;7:133-9. [CrossRef] 
12. Yılmaz M. Sağlık bakım kalitesinin bir ölçütü: Hasta memnuniyeti. C. U. Hemşirelik Yüksekokulu Dergisi 2001;5:69-73.

13. Young GJ, Meterko M, Desai KR. Patient satisfaction with hospital care: effects of demographic and institutional characteristics. Med Care 2000;38:325-34.

14. Schmidt LA. Patients' perception of nursing care in the hospital setting. J Adv Nurs 2003;44:393-9. [CrossRef]

15. Akin S, Erdoğan S. The Turkish version of The Newcastle Satisfaction With Nursing Care Scale used on medical and surgical patients. J Clin Nurs 2007;16:646-53. [CrossRef]

16. Şişe Ş. Hastaların hemşirelik hizmetlerinden memnuniyeti. Kocatepe Tıp Derg 2013;14:69-75.

17. Köşgeroğlu N, Acat MB, Karatepe Ö. Kemoterapi hastalarında hemşirelik bakımı memnuniyet ölçeği. Anadolu Psikiyatri Derg 2005;6:70-72.

18. Akın B, Çeber Turfan E. Doğuma hazırlık eğitimi alan ve almayan gebelerin doğumdan memnuniyetlerinin değerlendirilmesi. Uluslararası Hakemli Kadın Hastalıkları ve Anne Çocuk Sağlığı Derg 2016;8:1-16. [CrossRef]

19. Ercan I, Kan İ. Ölçeklerde güvenirlik ve geçerlik. Uludağ Üniv Tıp Fakültesi Derg 2004;30:211-6.
20. Gözüm S, Aksayan S. Kültürlerarası ölçek uyarlaması için rehber II. Psikometrik özellikler ve kültürlerarası karşılaştırma. Hemşirelik Araştırma Derg 2003;5:3-14.

21. Şencan $H$. Sosyal ve davranışsal ölçümlerde güvenilirlik ve geçerlilik 1. Baskı, Ankara: Seçkin Yayınevi; 2005.

22. Camacho F, Weisman C, Anderson R, Hillemeier M, Schaefer E, Paul I. Development and validation of a scale measuring satisfaction with maternal and newborn health care following child birth. Matern Child Health J 2012;16:997-1007. [CrossRef]

23. Yurdugül $H$. Ölçek geliştirme çalışmalarında kapsam geçerliği için kapsam geçerlik indekslerinin kullanılması. http://yunus. hacettepe.edu.tr/ yurdugul/3/indir/PamukkaleBildiri.pdf Erişim Tarihi:12.04.2016

24. Özdamar K. Paket Programlar İstatistiksel Veri Analizi. Eskişehir: Kaan Yayınevi; 2004.

25. Albayrak AS. Uygulamalı Çok Değişkenli İstatistik Teknikleri. Ankara: Asil Yayın Dağıtım; 2006.

26. Ateş $C$, Öztuna D, Genç Y. Sağlık araştırmalarında sınıf içi korelasyon katsayısının kullanımı. Turkiye Klinikleri J Biostat 2009;1:59-64. 